EESTI NSV TEADUSTE AKADEEMIA TOIMETISED. XVI KÖIDE

KEEMIA * GEOLOOGIA. 1967, NR. 1

ИЗВЕСТИЯ АКАДЕМИИ НАУК ЭСТОНСКОИ ССР. ТОМ ХVI

Химия * ГЕология. 1967, № 1

T. ЛЕСМЕНТ, С. ФАИНГОЛЬД

\title{
О МЕТОДИКЕ ОПРЕДЕЛЕНИЯ ПОЛОЖЕНИЯ ДВОЙНОЙ СВЯЗИ В МОНООЛЕФИНОВЫХ УГЛЕВОДОРОДАХ
}

Большое количество реакций, приводящих к получению поверхностно-активных веществ, полимерных материалов, фармацевтических препаратов, средств защиты растений и т. д., связано с участием моноолефиновых углеводородов. В связи с легкостью миграции двойной связи под действием кагализаторов обычно получается смесь изомеров, различающихся по своим свойствам. Знание закономерностей изомеризации двойной связи может помочь приблизиться к решению вопроса о получении веществ с заданными свойствами. До настоящего времени преимущественно изучалась изомеризация двойной связи моноолефинов для гомологов, содержащих до шести атомов углерода. Данные о закономерностях миграции двойной связи в длинноцепочных гомологах отсутствуют.

В последние годы широко используются реакции лрисоединения моноолефинов $\mathrm{C}_{8}-\mathrm{C}_{16}$ к ароматическим углеводородам и карбоновым кислотам. Катализаторами алкилирования служат галоидные металлы, сильные кислоты, соединения фтористого бора и алюмосиликаты [']. Например, при алкилировании бензола додеценом-1 в наиболее мягких условиях (наличие растворителя, большое соотношение бензол-алкен, низкие температуры и т. д.) всегда получаются все возможные изомеры, отличающиеся местом присоединения в алкильной цепи $\left[{ }^{1-4}\right]$. Использование додецилбензола для синтеза поверхностно-активных и моющих веществ приводит к получению смеси изомеров с резко отличающимися свойствами. Сознательно регулировать соотношение изомеров в смеси невозможно, так как отсутствуют данные о закономерностях изомеризации двойной связи.

Первым вопросом при решении этой задачи является изучение способа определения положения двойной связи в смеси моноолефиновых углеводородов, состоящей из соединений с одинаковым количеством углеродных атомов. В литературе отсутствуют данные о методике определения положения двойной связи, позволяющие быстро и надежно осуществить анализ. Непосредственная газо-жидкостная хроматография алкенов не может быть применена, так как времена удерживания отдельных изомеров в колонке совпадаюг. Наибольшей разделительной способностьіо обладает жидкая фаза твин $60-80$, но и в данном случае разделение изомеров недостаточно для количественного их определения. Для иллюстрации в табл. 1 приведены времена удерживания пяти нзомеров нормального октена в форме индексов Ковача ["]. Анализ был проведен на УX-I с использованнем 5-метровой колонки, наполненной хромосорбом $\mathrm{P}$ и твином 80 (жидкая фаза).

Таблица 1

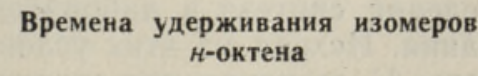

\begin{tabular}{l|l}
\hline Изомер н-октена & $I$ \\
\hline & \\
\hline Октен-1 & 823 \\
Октен-2 транс & 838 \\
Октен-2 цис & 849 \\
Октен-3 & 822 \\
Октен-4 & 816
\end{tabular}


Лучшее разделение изомеров получается при использовании капиллярной хроматографии. Но этот способ также имеет недостатки, препятствующие его применению для наших целей. Главный из них - трудность воспроизведения результатов на различных разделительных колонках. Это объясняется тем, что колонки диаметром $0,2-0,3$ мм и длиной 40-60 м неодинаковые и жидкая фаза не всегда распределяется равномерно.

Определение положения двойной связи пугем расшифровки спектров различных изомеров при исследовании методом комбинационного рассеяния света также невозможно из-за диффузности спектров и слияния близких линий изомерных углеводородов в пслосы [ө].

В последнее время $\Phi$. Азингер с сотрудниками $\left[{ }^{7}\right]$ применили для определения местоположения двойной связи в длинноцепочных углеводородах известный метод озонолиза с последующим окислением продуктов щелочной суспензией окиси серебра до кислот [7]. По этому способу кислоты выделяются из водных растворов, метилируются и метиловые эфиры анализируются путем газо-жидкостной хроматографии. Қислоты трудно разделяются хроматографически, так как возникает димеризация свободных кислот, и пока не известны стационарные фазы, которые предотвращали бы это явление [?]. Поэтому значительно легче получить метиловые эфиры кислот, которые хорошо разделяются методом газо-жидкостной хроматографин.

Недостатком методики $Ф$. Азингера является необходимость экетракции киелот из водных растворов. При наличии в водном растворе нескольких кислот, особенно с небольшим числом углеродных атомов, обладающих большой растворимостью, количественно выделить их не удается. Поэтому анализ известных смесей по методу Ф. Азингера не привел к верным и воспроизводимым результатам.

\section{Экспериментальная часть}

Изучение методики включало следующие основные процессы: 1) синтез индивидуальных изомеров нормальных октенов, отличающихся положением двойной связи; 2) изучение озонолиза индивидуальных октенов и их смесей с доокислением озонидов до кислот; 3) изучение метода извлечения кислот из растворов; 4) синтез индивидуальных метиловых эфиров масляной, валериановой, капроновой и энантовой кислот и определение времени их удерживания в колонке газового хроматографа; 5) изучение комплекса процессов нахождения положения двойной связи в известной смеси изомеров нормальных октенов и оценка полученных результатов.

1. Синтез исходных октенов. В литературе имеется довольно много ссылок на методику препаративного синтеза индивидуальных алкенов заданного строения (см., напр., [9]). Были испробованы почти все основные пути синтеза. При выборе того или иного метода учитывались не только выходы конечных продуктов, их чистота и продолжительность синтеза, но и дефицитность реактивов и возможность безопасного проведения синтеза в лабораторных условиях без специального оборудования. Исходя из этих условий, были проверены следующие пути синтеза: 1) дегидратация спиртов; 2) присоединение магнийбромалкилов к бромистому аллилу; 3) бромирование дивинила с последующим присоединением к 1,4-дибромбутену магнийбромалкилов; 4) получение ацетиленидов натрия и присоединение к ним бромалканов с последующим восстановлением алкинов до алкенов; 5) синтез по Бурд.

Первые два способа позволяют легко и с хорошими выходами получать 1-алкены. Чистота получаемых 1-алкенов превышает 99\%. Выбор метода диктуется наличием исходных реактивов: в первом случае нормального первичного октилового спирта, а во втором - бромистого 
аллила и нормального 1-бромалкана. Получение алкенов из 1,4-дибромбутена удобно для получения октена-4, хотя выходы относительно невысокие (до 20\%). При помощи этого способа было получено некоторое количество октена-4, но накопление значительного количества реактива затруднено из-за токсичности дибромбутена, действующего на слизистые оболочки глаз. Менее токсичны хлорпроизводные, но выход конечных продуктов при этом снижается почти в два раза.

Синтез через ацетилениды является наиболее удобным препаративным способом получения любых изомеров алкенов. Нами проверено несколько схем, отличающихся последовательным проведением следующих реакций:

1. $\mathrm{HC} \equiv \mathrm{CH}+2 \mathrm{NH}_{2} \mathrm{Na} \rightarrow \mathrm{NaC} \equiv \mathrm{CNa}+2 \mathrm{NH}_{3}$

$\mathrm{NaC} \equiv \mathrm{CNa}+2 \mathrm{CH}_{3} \mathrm{CH}_{2} \mathrm{CH}_{2} \mathrm{Br} \rightarrow \mathrm{CH}_{3} \mathrm{CH}_{2} \mathrm{CH}_{2} \mathrm{C} \equiv \mathrm{CCH}_{2} \mathrm{CH}_{2} \mathrm{CH}_{3}+$ $+2 \mathrm{NaBr}$

2. $\mathrm{HC} \equiv \mathrm{CH}+\mathrm{NH}_{2} \mathrm{Na} \rightarrow \mathrm{HC} \equiv \mathrm{CNa}+\mathrm{NH}_{3}$

$\mathrm{HC} \equiv \mathrm{CNa}+\mathrm{RBr} \rightarrow \mathrm{HC} \equiv \mathrm{CR}+\mathrm{NaBr}$

$\mathrm{HC} \equiv \mathrm{CR}+\mathrm{NH}_{2} \mathrm{Na} \rightarrow \mathrm{NaC} \equiv \mathrm{CR}+\mathrm{NH}_{3}$

$\mathrm{NaC} \equiv \mathrm{CR}+\mathrm{R}_{1} \mathrm{Br} \rightarrow \mathrm{R}_{1} \mathrm{C} \equiv \mathrm{CR}+\mathrm{NaBr}$

3. $\mathrm{RCH}=\mathrm{CH}_{2}+\mathrm{Br}_{2} \rightarrow \mathrm{RCHBr}-\mathrm{CH}_{2} \mathrm{Br} \underset{-2 \mathrm{HBr}}{\stackrel{\mathrm{KOH}}{\longrightarrow}} \mathrm{R}-\mathrm{C} \equiv \mathrm{CH}$,

цальше синтез идет так же, как и во втором случае.

Селективное восстановление алкинов до алкенов легко осуществляется двумя способами: 1) водородом в присутствии палладия и 2) натрием в жидком аммиаке. В первом случае получается цицс-изомер, а во втором - транс. Наиболее важной является вторая схема, которая позволяет осуществить синтез алкенов любого строения с хорошими выходами, без употребления дефицитных реактивов. По этой схеме были синтезированы все октены. Особенно хороша она для получения октена- 2 и октена-3, так как октен-4 легко получается по первой схеме. Получение алкинов путем бромирования алкенов с последующим дегидробромированием дибромалканов удобно лишь в тех случаях, когда имеются соответствующие индивидуальные алкены-1.

Синтез октена по Бурд осуществлялся в четыре стадии [10]:

$\mathrm{O}$

a) $\mathrm{CH}_{3} \mathrm{CH}_{2} \mathrm{CH}_{2} \mathrm{C}+\mathrm{C}_{2} \mathrm{H}_{5} \mathrm{OH}+\mathrm{HCI} \rightarrow \mathrm{CH}_{3} \mathrm{CH}_{2} \mathrm{CH}_{2} \mathrm{CHCIOC}_{2} \mathrm{H}_{5}+\mathrm{H}_{2} \mathrm{O}$ $\mathrm{H}$

б) $\mathrm{CH}_{3} \mathrm{CH}_{2} \mathrm{CH}_{2} \mathrm{CH}-\mathrm{OC}_{2} \mathrm{H}_{5}+\mathrm{Br}_{2} \rightarrow \mathrm{CH}_{3} \mathrm{CH}_{2} \mathrm{CH}-\mathrm{CH}-\mathrm{OC}_{2} \mathrm{H}_{5}+\mathrm{HCI}$<smiles>Cl[Mg]Br</smiles>

B) $\mathrm{CH}_{3} \mathrm{CH}_{2} \mathrm{CHBr}-\mathrm{CHBr}-\mathrm{OC}_{2} \mathrm{H}_{5}+\mathrm{MgBrC}_{4} \mathrm{H}_{9} \rightarrow$

$$
\rightarrow \mathrm{CH}_{3} \mathrm{CH}_{2} \mathrm{CHBr}-\mathrm{CH}+\mathrm{MgBr}_{2}
$$

$\mathrm{C}_{4} \mathrm{H}_{9}$

г) $\mathrm{CH}_{3} \mathrm{CH}_{2} \mathrm{CHBr}-\mathrm{CH}+\mathrm{Zn} \rightarrow \mathrm{CH}_{3}-\mathrm{CH}_{2} \mathrm{CH}=\mathrm{CH}-\mathrm{C}_{4} \mathrm{H}_{9}$

$\mathrm{OC}_{2} \mathrm{H}_{5}$ 
По этому способу получается индивидуальный октен-3 удовлетворительной чистоты, но выход его небольшой. Более удобно получать алкены по ацетиленовому способу. Свойства полученных и используемых для дальнейших исследований октенов приведены в табл. 2.* Bce синтезированные. октены обладают свойствами, позволяющими использовать их в качестве эталонов для определения соотношения между отдельными изомерами в смеси.

Таблица 2

Характеристика н-октенов

\begin{tabular}{|c|c|c|c|c|c|c|c|c|}
\hline & \multicolumn{2}{|c|}{ Октен-1 } & \multicolumn{2}{|c|}{ Октен-2 } & \multicolumn{2}{|c|}{ Октен-3 } & \multicolumn{2}{|c|}{ Октен-4 } \\
\hline & 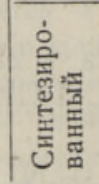 & 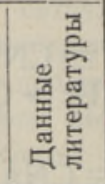 & 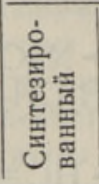 & 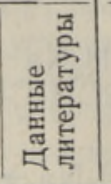 & 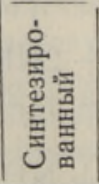 & 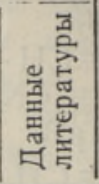 & 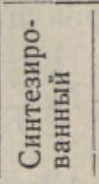 & 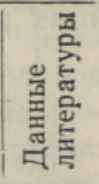 \\
\hline Температура кипения, ${ }^{\circ} \mathrm{C}$ & $\begin{array}{l}121- \\
122\end{array}$ & $\begin{array}{l}122,3- \\
122,5\end{array}$ & $\begin{array}{l}124- \\
125\end{array}$ & 125 & 123 & 122,9 & 122 & $\begin{array}{l}122- \\
123\end{array}$ \\
\hline Удельный вес $d_{4}{ }^{20}$ & 0,7559 & 0,7223 & 0,7211 & 0,7250 & 0,7474 & 0,7181 & 0,7206 & 0,7184 \\
\hline Показатель преломления $n_{D}{ }^{20}$ & 1,4096 & 1,4097 & 1,4138 & 1,4150 & 1,4118 & 1,4136 & 1,4144 & 1,4140 \\
\hline
\end{tabular}

* Синтез октенов осуществлен совместно со ст. научн. сотр. Г. Степановой.

2. Озонолиз. Реакция присоединения озона к олефинам по двойной связи часто используется для определения положения двойной связи в ненасыщенных соединениях.

По способу Ф. Азингера озониды окисляются щелочной суспензией окиси серебра до кислот с выходом $90-98 \%$.

Для проведения озонолиза был сконструирован лабораторный аппарат по типу озонатора, предложенного в работе [ $\left.{ }^{11}\right]$.

Превращение кислорода в озон осуществляется с помощью четырех трубок Бертло, жестко спаянных между собой. Последняя трубка соединена с реакционными сосудами при помощи шлифов. Для озонатора используется трансформатор с рассеянием (типа газосветных установок) с выходным напряжением 13000 в, включенный через ЛАТР.

Из реакционного сосуда кислород, содержащий озон, поступает в сосуд, заполненный нейтральным 5\%-ным раствором йодистого калия. Озонирование прекращается, когда последний пожелтеет, так как непоглощенный озон вытесняет йод $\left(\mathrm{O}_{3}+2 \mathrm{KJ}+\mathrm{H}_{2} \mathrm{O}=\mathrm{J}_{2}+2 \mathrm{KOH}+\mathrm{O}_{2}\right)$.

3. Извлечение кислот из растворов. По Ф. Азингеру, после доокисления озонидов щелочной суспензией окиси серебра непрореагировавшую часть последней растворяют азотной кислотой, при этом карбоновые кислоты всплывают на поверхность водного раствора.

В нашей работе с $н$-октеном необходимо было определить кислоты, начиная с масляной, которая неограниченно растворяется в воде. Экстракция кислот пентаном или гексаном не дала желаемых результатов. Поэтому мы после доокисления озонидов непрореагировавшую окись серебра отфильтровывали, а фильтрат упаривали досуха. При этом кислоты получаются в форме $\mathrm{Na}$-солей.

4. Синтез индивидуальных метиловых эфиров карбоновых кислот. В настоящей работе исследовались н-октены с различным положением двойной связи, и в результате озонолиза и дальнейшего окисления получалась энантовая кислота из октена-1; капроновая - из октена-2; валериановая - из октена-3 и масляная - из октена-4. Для иденти- 


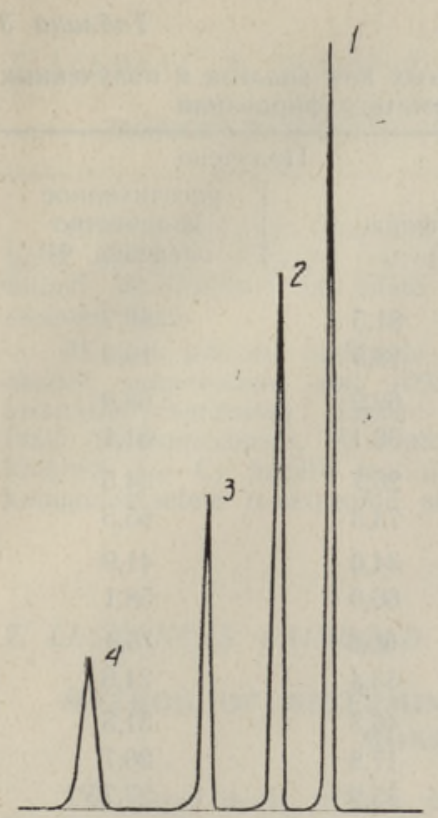

Рис. 1. Хроматограмма смеси метиловых эфиров масляной (1), валериановой (2), капроновой (3) и энантовой (4) кислот.

фикации метиловых эфиров вышеуказанных кислот были синтезированы эталонные метиловые эфиры масляной, валериановой, капроновой и энантовой кислот. На рис. 1 приведена хроматограмма эталонной смеси метиловых эфиров кислот $\mathrm{C}_{4}-\mathrm{C}_{7}$.

Анализ проводился при помощи хроматографа типа УX-I на 6-метровой колонке, наполненной ИНЗ-600 с вели-

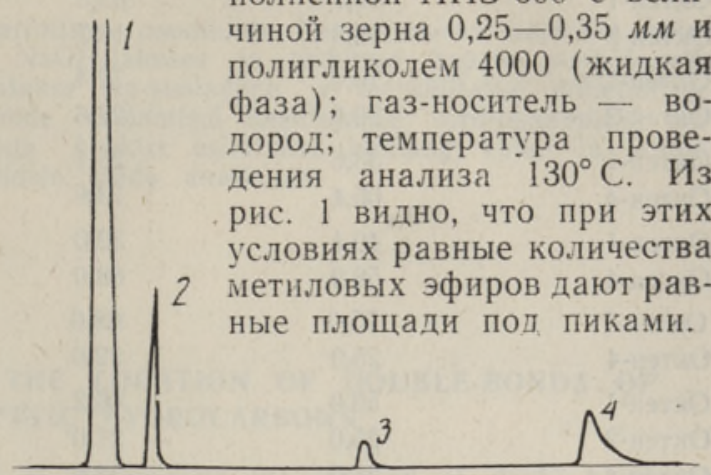

Рис. 2. Хроматограмма опыта 6 (табл. 3): 1 - ацетон, 2 - метилбутират, 3 - метилкапроат, 4 - метнлэтантат.

5. Изучение комплекса процессов нахождения положения двойной связи в известной смеси изомеров $H$-октенов и оценка полученных результатов. В результате вышеизложенного методика определения изомеров $н$-октена сводится к следуюшему: смесь олефинов растворяется в гексане и подвергается озонированию при температуре $-15 \div-10^{\circ}$. После окончания озонирования раствор озонидов в гексане осторожно приливается к суспензии окиси серебра в 10\%-ном растворе $\mathrm{NaOH}$. Дальнейшее окисление озонидов в кислоты проводится в течение 6 и при постоянном перемешивании и нагревании реакционной смеси на кипящей водяной бане. После отфильтровывания непрореагировавшей окиси серебра и упаривания фильтрата досуха осадок, содержащий $\mathrm{Na-coли} \mathrm{карбоновых} \mathrm{кислот,} \mathrm{растирают,} \mathrm{помещают} \mathrm{в} \mathrm{трехгорлую} \mathrm{колбу,}$ снабженную мешалкой, заливают ацетоном и добавляют немного концентрированной серной кислоты. Затем при нагревании и постоянном перемешивании закапывают расчетное количество диметилсульфата. При действии диметилсульфата на $\mathrm{Na}$-соли карбоновых кислот образуются метиловые эфиры кислот. Выпадающий в осадок сульфат натрия отфильтровывается, а раствор хроматографируется.

Для иллюстрации на рис. 2 приведена хроматограмма опыта 6 (табл. 3). Соотношение площадей пиков дает соотношение изомеров н-октенов в смеси. При расчете необходимо учитывать коэффициент, полученный от деления молекулярного веса олефина на молекулярный вес метилового эфира соответствующей кислоты, а также то, что в случае октена- 4 ' из одной молекулы олефина образуются две одинаковые молекулы масляной кислоты.

В табл. 3 показаны рассчитанные и полученные количества метиловых эфиров кислот и соответствующих олефинов при проведении анализа модельных смесей различных изомеров н-октена. 
Сравнение различных количеств изомеров н-октенов, взятых для анализа и полученных расчетным путем после озонирования и хроматографирования

\begin{tabular}{|c|c|c|c|c|}
\hline \multirow[b]{2}{*}{ Олефин } & \multicolumn{2}{|c|}{ Взято } & \multicolumn{2}{|c|}{ Получено } \\
\hline & $\begin{array}{l}\text { олефина, } \\
\text { вес. \% }\end{array}$ & $\begin{array}{c}\text { рассчитанное } \\
\text { количество } \\
\text { эфира, \% }\end{array}$ & эфира, \% & $\begin{array}{r}\text { рассчитан } \\
\text { количест } \\
\text { олефінна, }\end{array}$ \\
\hline Октен-1 & 81,7 & 83,3 & 81,5 & 80,7 \\
\hline Октен-2 & 18,3 & 16,7 & 18,5 & 19,3 \\
\hline Октен-1 & 70,4 & 72,4 & 69,9 & 68,9 \\
\hline Октен-2 & 29,6 & 27,6 & 30,1 & 31,1 \\
\hline Октен-1 & 33,6 & 26,1 & 26,7 & 34,5 \\
\hline Октен-4 & 66,4 & 73,9 & 73,3 & 65,5 \\
\hline Октен-1 & 40,1 & 32,0 & 34,0 & 41,9 \\
\hline Октен-4 & 59,9 & 68,0 & 66,0 & 58,1 \\
\hline Октен-1 & 75,0 & 68,0 & 66,6 & 75,4 \\
\hline Октен-4 & 25,0 & 32,0 & 33,4 & 24,6 \\
\hline Октен-1 & 50.0 & 46,2 & 46,3 & 51,5 \\
\hline Октен-2 & 25,0 & 21,0 & 17,8 & 20,7 \\
\hline Октен-4 & 25,0 & 32,8 & 35,9 & 27,75 \\
\hline
\end{tabular}

Хорошее совпадение результатов дает возможность рекомендовать приведенную методику для определения и количественной оценки содержания нормальных олефинов с различным положением двойной связи в цепи.

В связи с появлением в последнее время озонаторов промышленной производительности метод озонолиза олефинов может быть также применен для получения из соединений, содержащих двойную связь, дикарбоновых кислот, первичных спиртов и других дефицитных продуктов.

\section{ЛИТЕРА Т У РА}

1. Файнгольд С. И., Синтетические моющие средства из нефтяного и сланцевого сырья, Л., 1964.

2. A s inger F., Ge iseler G., B e et z W., Chem. Ber., 92, Nr. 3, 755 (1959).

3. Ols on A. C., Ind. Eng. Chem., 52, Nr. 10, 833 (1960).

4. Tjepkema J. J., Paulis B., Huyser H. W., 5. World Petr. Congress, 4, 21 (1959).

5. Anal, Chem., 36, No. 8, 31A (1964).

6. Левина Р. Я., Мезенцева Н. Н., Акишин П. А., Вестн. МГУ, № 6, 115 (1949).

7. Asinger F., Fell B., Collin G., Chem. Ber., 96, Nr. 3, 716 (1963).

8. J a mes A. T., Martin A. I. P., Bioch. J., 63, No. 1, 144 (1956).

9. Левина Р. Я., Уеп. химии, 13, вып. 5,513 (1949).

10. Boord C. E., Henne A. L., Greenlee K. W., Perilstein W. L., Derf e r I. M., Ind. Eng. Chem., 41, No. 3, 609 (1949).

11. Смит Л., Гринвуд Ф., Хэрдлик О., Синтезы органических препаратов; Сб. 4, М., 1959.

Институт химии

Академии наук Эстонской ССР
Поступнла в редакцию 5/III 1966 
T. LESMENT, S. FAINGOLD

\section{MONOOLEFIINSETE SUSIVESINIKE KAKSIKSIDEMETE ASUKOHA MÄARAMISE MEETOD}

Artiklis esitatakse meetod kaksiksidemete asukoha määramiseks $n$-olefiinide puhul. Selle abil on võimalik uurida isomerisatsiooninähtusi, mis kulgevad katalüsaatorite toimel alküülimisel ja teiste reaktsioonide puhul, millest vôtavad osa $n$-olefiinsed süsivesinikud.

Meetod seisneb olefiinide osoneerimises, osoniidide hapendamises hapeteks hõbeoksiidi suspensiooni abil $10 \%$-lises $\mathrm{NaOH}$-lahuses ja tekkinud hapete metüülestrite kromatografeerimises. Happed eraidatakse Na-sooladena ja metüülitakse dimetüülsulfaadi atsetonilahuses. Kromatogrammide hindamisel kasutatakse võrdlusandnieid etaloonsete $\mathrm{C}_{4}-\mathrm{C}_{7}$ hapete metüülestritega. Artiklis esitatakse hinnang kahe- ja kolmekomponentsetele $n$-okteenide süsteemidele, mida analüüsiti.

\section{T. LESMENT, S. FAINGOLD}

\section{METHOD OF DETERMINING THE LOCATION OF DOUBLE-BONDS OF MONOOLEFINIC HYDROCARBONS}

The paper deals with a method of determining the location of double-bonds in the case of $n$-olefins. With its help, it is possible to study phenomena of isomerisation formed as an effect of catalysts during alkylation and other reactions in which $n$-olefinic hydrocarbons participate.

The method consists of an ozonisation of olefins, oxidation of ozonides into acids by a suspension of argentine oxide in a 10 -percent solution of $\mathrm{NaOH}$, and in subjecting the methylesters of acids obtained to chromatography. The acids are separated as Na-salts, and they are methylised in a solution of dimethyl-sulfate acetone. At the estimation of the chromatograms, comparative data with the methylesters of standard $\mathrm{C}_{4}-\mathrm{C}_{7}$ acids are applied. In the paper, an estimation of the analysed two- and three-component $n$-octane systems is presented. 